Interdisciplinary Studies of Complex Systems

No. 16 (2020) 106-116

(C) Н. Кондратьева

https://doi.org/10.31392/iscs.2020.16.106

\title{
МУЗЫКА КАК ПОСТИЖЕНИЕ СМЫСЛОВ
}

\section{Наталия Кондратъева ${ }^{1}$}

\begin{abstract}
This article is an essay about composers and music of the twentieth century.

It is about the big experiment to create new musical forms and «thinking in music».
\end{abstract}

\begin{abstract}
«Если в основе вселенной лежат вибрации, не означает ли это,

что вселенная ведет себя как музыкальный инструмент?»
\end{abstract}

Стефон Александр «Джаз Физики»

Если рай очертить границей и замкнуть эту границу на замок, то рай может превратиться в ад. Сегодня, когда мир накрыла пандемия нового вируса от которого нет вакцины и страны ввели жесткий карантин для своих граждан, многие получили то, что условно могли называть раем, - можно выспаться, можно сколько хочешь читать книги и смотреть фильмы, заниматься любимыми делами, а если есть сад, бассейн... Но почему-то через две-три недели очень хочется выйти за пределы этого рая и со временем он становится все тягостнее. Сознание начинает обращать внимание на мысли, которые раньше проходили сквозь него не оставляя следа. Начинается поиск новых смыслов.

В 2002 году Артем Варгафтик снял фильм «Альфред Шнитке и красота в музыке». В этом фильме он попытался рассмотреть творчество композитора с точки зрения попытки выйти из «рая» всей известной уже музыки и посмотреть что же находиться за этими границами. Это были поиски новых смыслов...

Принято считать, что современная наука берет свое начало с сэра Исаака Ньютона, его фундаментального труда «Математические начала натуральной философии» («Математические основы физики»), теории тяготения и целого ряда других замечательных его открытий. В сохранившихся тетрадях Ньютона его кембриджского периода видно, что ученый занимался так же теорией музыки как частью математики. В это время великий Иоган Себастиан Бах, используя математику, открыл новые горизонты музыкальных возможностей в полифонии и гармонии, обобщал темперацию.

\footnotetext{
${ }^{1}$ nkondr24@gmail.com
} 
При дворе Фридриха II Бах впервые играл на новом инструменте, пианино. И мог встретить там Леонарда Эйлера, который так же рассматривал музыку как часть математики и ввел в нее понятие «градуса красоты» (гармонии).

В то время распространение новых знаний и любой другой информации зависело, как и тысячи лет назад, от количества лошадей в упряжке и ветра под парусом. Но в человеческое сознание все шире входило понятие мысли и идеи, научная мысль способствовала быстрому развитию техники, изобретения изменяли жизнь. Мысль становилась пространством и музыка становилась все более ментальной.

Шопенгауер писал: «Музыка выражает квинтэссэнцию жизни и в отличие от других искусств не есть отражение идей, а есть метафизическое явление непосредственной идеи и, поэтому, есть высшая форма познания мира».

Появление поездов, автомобилей, самолетов, телеграфа, телефона, компьютера изменили мир. Начиналась эпоха, которую Вернадский назвал «От биосферы к ноосфере». И музыка как зеркало времени искала новые формы и новое звучание. В XX веке венские классики во главе с Шенбергом, московские классики второй половины XX века Шнитке, Губайдулина, Денисов, английский композитор Бенджамин Бриттен, американец Филип Гласс, немецкие композиторы Штокхаузен и Лахенманн, французский композитор Ксенакис и итальянский Луиджи Ноно, украинский композитор Сильвестров и целый ряд других композиторов провели грандиозный эксперимент в музыке. Все чаще композиторы через музыку пытались выражать конкретные философские идеи и концепции, все чаще обращались к математике и пытались через «материальную» музыкальную форму найти отражение неслышимой космической музыки...

Альфред Шнитке в своих интервью рассказывал, что сперва он, как и другие студенты консерватории, рассчитывал музыку по формулам и надеялся, что когда будет найдена самая совершенная математическая формула, можно будет создать самое совершенное музыкальное произведение. Но рассчитанная музыка получалась скучной, и если удавалось написать что-то интересное, то это, как правило, было следствием ошибки в расчетах. И только позже, в период большого эмоционального переживания Шнитке впервые «услышал» музыку и записал ее. Произошло то, что в науке известно как озарение. Потом возникло ощущение нахождения все музыки (прошлой, настоящей и будущей) одновременно где-то во вселенной. Эту философскую концепция он назвал полистилистикой и написал полистилистические произведение, такие, как например, Concerto Grosso №1. Полистилистика заключалась и в синтезе эксперимента, озарений и обращений к «старой» школе.

Музыка все чаще воспринималась как космическое, вселенское явление и наоборот. Наряду с этим часто исчезала мелодия, она приносилась в жертву прямому доступу авторской концепции до слушателя. Часто музыка писалась для музыкантов и была понятна только им. В итоге всех побед и поражений XX век создал подлинные музыкальные шедевры и, проделав большой музыкальный эксперимент обогатил музыкальное искусство новым пониманием мира. 
В 2015 году вышла книга Филипа Гласса «Слова без Музыки» («Words without Music»). Выдающийся американский композитор написал эту книгу к своему восьмидесятилетию и в комментарии к этой книги можно прочесть, что Гласс, оглядываясь на свою жизнь видит ее как протянувшееся во времени и пространстве «место музыки», куда можно вернуться как в Балтимор или Индию, и там «думать музыку», так как музыка Филипа Гласса это и есть его мысль и слово.

Композиторы прошлого века часто вынуждены были прибегать к словам, к объяснению своей музыки, т. к. это был единый процесс «думания музыки». Они оставили нам большой архив своих рассуждений о музыке. Этот архив, оставленный музыкантами, большой дар всем нам, он не только позволяет глубже понять их творчество, но и помогает в осознании философского мышления в музыке XX века. Александр Скрябин, Арнольд Шенберг, Антон Веберн, Альфред Шнитке, София Губайдулина, Эдисон Денисов, Валентин Сильвестров, - в своих интервью, записках, статьях и докладах обсуждали ощущения в музыке таких понятий как пространство и время, говорили об особенности музыкального творчества и значении музыки как способа познания новых смыслов и творения новых форм. Из этих «слов без музыки» сегодня можно составить представление и том, как «думали музыку» в XX веке:

АНТОН ВЕБЕРН: «Очевидно, существовала некая потребность, некая необходимость, которая вызвала к жизни то, что мы называем музыкой. Необходимость выразить мысль, которую иначе, чем в звуках не выразить». [1]

ЭДИСОН ДЕНИСОВ: «Музыка может туда проникнуть, куда слово не проникнет». [2]

БЕНДЖАМИН БРИТТЕН: «Когда я создаю музыку, я не мыслю ее в отрыве от идеи». Мысль в ХХ веке сыграла доселе невиданную роль. Общая теория относительности Эйнштейна заставила по новому осмысливать окружающий нас мир. Пространство получило возможность искривляться, время становиться относительным.

АЛЬФРЕД ШНИТКЕ: «В действительности линейность времени это не линия. Это бесчисленное количество выхваченных из разных пространств точек. И вот возникает такое ощущение бесконечного леса времен, где каждая линия времени - другая, каждое дерево растет по своему. И все, что в прошлом возникло, возникло на деревьях, которые живут и сейчас... У меня есть ощущение сосуществования всех времен и возможности их появления независимо друг от друга абсолютно всегда». [3]

СОФЬЯ ГУБАЙДУЛИНА: «Хочу достичь своей музыкой того, что все хотят достичь. То есть, осуществить настоящее длящееся время, которого в жизни нет. В жизни-то нет настоящего длящегося времени - мы не имеем вообще настоящего времени в жизни, мы все время переходим из прошлого к будущему, а настоящего мы не имеем ни одного мгновения. И это мгновение, по-существу, только в искусстве можно достичь, когда настоящее длится, и оно длится с помощью музыкальной формы». [4]

АЛЬФРЕД ШНИТКЕ: «У меня появилось сейчас то, чего я больше всего всегда хотел: появилась бесконечность каждой секунды». [3] 
АЛЕКСАНДР СКРЯБИН: «Вам не кажется, что музыка заколдовывает время, может его вовсе остановить? ... Ритм - заклинание времени. И в этом смысл ритма. Творческий дух посредством ритмов вызывает самое время и управляет им». [5]

В XX веке наука не только исследовала радиоактивность и создала атомную бомбу, ученые открыли «темную» энергию и «темную» материю, которые в сумме занимают до $95 \%$ объема Вселенной. Определение «темные» не носит негативного значения, темные - значит неизведанные, недоступные нашему слуху и зрению, мнимые с точки зрения нашего физического восприятия.

Исследование этой мнимой стороны Вселенной началось и в музыке. Начался поиск бесформенной музыкальной субстанции, поиск «звучащей Тишины». (Альфред Шнитке подарил Г. Рождественскому формулу «звучащей Тишины», - фермата над паузой, под которой три форте,- такая длящаяся без ограничения времени очень громкая пауза).

АЛЕКСАНДР СКРЯБИН: «Тишина есть тоже звучание... В тишине есть звук. И пауза звучит всегда... Знаете, я думаю, что может быть даже музыкальное произведение, состоящее из молчания.

Вы не пробовали производить такой опыт. Во время игры представит себе такие дополнительные, воображаемые звуки, как бы мнимые контрапункты? Они очень меняют все отношение к исполняемому... Все как-то по-иному расцветает». [5]

ВАЛЕНТИН СИЛЬВЕСТРОВ: ММуыка должна рождаться из молчания. Музыка - это не то, что звучит, она в структуре молчания. Вот, например, Пятая симфония Бетховена. Ее зачин: та-ра-та-та... та-ра-тата... - это обычные фигуры, которые бытовали тогда и бытуют сейчас. Но за пределами этой музыки уже было накоплено настолько сильное элекричество молчания, что оно просто прорвало, как молния». [11]

Поиск новых форм, скорее бесформенности (дематериализации) разрушал классические гармонии, выявлявшиеся в созвучных пропорциях. Свободная атональность вела к распаду музыкальной формы. Куда-то уходила красота. Или нарождалась новая?

АРНОЛЬД ШЕНБЕРГ: «Музыка не должна украшать, она должна быть истинной и только...».

Но как истину, т.е. знание более высоких планов бытия, высказать без искажения языками более грубого плана ? «Мысль изреченная есть ложь»?

АЛЕКСАНДР СКРЯБИН: «Творить - значит прежде всего себя ограничивать, никогда творческая греза не может быть облечена до конца в плоть... Творчество есть отпечаток духа на материи, и это достигается только ценой известной жертвы, именно жертвы ограничения».

АЛЬФРЕД ШНИТКЕ: «Одним из очень ярких выражений этой проблемы (невозможности воплотить замысел полностью) явилась опера Шенберга «Моисей и Аарон». Два центральных образа оперы - Моисей, наделенный даром мысли (ему дано слышать и постигать истину, но он не способен ее рассказывать людям), и его брат Аарон, наделенный даром слова (он является «переводчиком» Моисея, интерпретатором и распространителем его мыслей), воплощают по сути две стороны души самого 
Шенберга: его стремление к чистой музыкальной мысли, очищенной от материальных, жанрово-семантических признаков, и догматическое миссионерство, требующее «материализованньх», переведенных на язык логики конструктивных норм. Именно трагическая невозможность реализации «чистой мысли»,... толкнула его вслед за освободительным порывом в атональность к созданию закрепляющих новую истину заповедей - системы додекафонии.

Что додекафония лишь компромисс, «перемирие», Шенберг отлично осознавал: практически он сам и разбил свои скрижали...».

О додекафонии написано очень много. Если очень кратко,- октава состоит из 12 полутонов. В традиционной европейской музыке используются лады из 7 звуков, с неравными между ними расстояниями: где-то тон, где-то полутон. Это неравенство создает иерархию, в которой одни звуки более устойчивые, другие менее. Эта музыкальная структура отвечает человеческому музыкальному восприятию, основанному на стремлении к определенным консонансным созвучиям, определенным числовым соотношениям. Еще пифагорийцы заметили, что две звучащие струны определяют консонанс, если их длины относятся как целые числа:

\section{$1: 2$ октава \\ $2: 3$ квинта \\ $3: 4$ кварта}

Семиступенчатая иерархия отвечает некоторой закономерности нашего мира: семь нот музыкальной октавы и семь цветов радуги (основного спектра), семь этажей Вавилонской башни и семь свободных наук Пифагора. ... Даже в химии мы имеем дело с правилом октавы: в 1865 г. английский химик и музыкант Дж. Ньюлендс разместил химические элементы в ряд по возрастанию относительны атомных масс и заметим, что каждый восьмой элемент подобен элементу, от которого производится отсчет. Закономерность, обнаруженную Ньюлендсом, назвали правилом октавы:

\section{$\begin{array}{llllllllllllllllllllllll}\mathrm{H} & \mathrm{Li} & \mathrm{Be} & \mathrm{B} & \mathrm{C} & \mathrm{N} & \mathrm{O} & \mathrm{F} & \mathrm{Na} & \mathrm{Mg} & \mathrm{Al} & \mathrm{Si} & \mathrm{P} & \mathrm{S} & \mathrm{CL} & \mathrm{K} & \mathrm{CA}\end{array}$ до ре ми фа соль ля си до ре ми фа соль ля си до ре ми}

Надо заметить, что при больших относительных атомных массах правило нарушается. Да и вся наша жизнь по календарю основана на неделях - октавах. Правда, недели составляют 12 месяцев в году, следуя кругу зодиака...

А теперь если представить, что ладовая иерархия отменяется и все 12 полутонов равны (как 12 рыцарей круглого стола) и создать последовательность из 12 неповторяющихся звуков как некоторую структуру? dodeka(греч.) - двенадцать. Ряд вычислений позволяет предположить, что форма Вселенной представляет додекаэдр, приближенный к сфере, отсюда и космические ритмы могут быть связаны с этой структурой. Платон называл додекаэдр символом эфира, того, что сегодня ученые называют «темной» материей. Додекафония - явление не случайное, но ее тайны еще не раскрыты.

Однако, вернемся к поиску истины.

АЛЬФРЕД ШНИТКЕ: «Каждый пытается прорваться к непосредственному выражению некоей слышимой им прамузыки, которая еще не уловлена. Это толкает композитора на поиски новой техники, потому что 
он хочет с ее помощью услышать то, что в нем звучит. Возникают бесконечные попытки отбросить все условности и создать без них нечто новое... Вот эти многочисленные попытки приблизиться к непосредственному выражению музыки, непрерывное обращение к обертонам, постижение новых рациональных приемов и приближение к истине открывают все новые и новые поля недостижимости. Этот процесс продолжается бесконечно. Поэтому воплощение замысла всегда является и его ограничением». [6]

Сочинить, придумать, рассчитать математически или услышать музыку?

АЛЬФРЕД ШНИТКЕ: (о двойном концерте для гобоя, арфы и струнного оркестра): «Что касается техники, то это не додекафонное сочинение. Все оно основано на использовании прогрессии. Такая прогрессия используется многими - это решето Эратосфена - ряд совершенных чисел, которые делятся только на единицу и на себя...».

АЛЕКСАНДР СКРЯБИН: (о седьмой сонате) «Я всегда признаю, что математика в композиции должна играть большую роль.У меня бывает иногда целое вычисление при сочинении, вычисление формы. И вычисление модуляционного плана. Он не должен быть случайным, - геометрическим, иначе не будет кристаллической формы. Вот схемы как модуляционно тональности движутся сначала по секстам, потом по квинтам, потом по квартам и так далее, все суживая свой «шаг»....

Мне здесь для формы нужно было два такта. Нужно, чтобы форма получилась как шар, совершенная как кристалл... Шар - это геометрический образ наибольшей завершенности. Это рациональный момент в творчестве». [5]

АЛЬФРЕД ШНИТКЕ:(о «Реквиеме»): «Тут - тихий Sanctus. До середины этой части, во всяком случае, все мне приснилось, это хорошо помню. Это был подарок. И для меня это было очень важным - я этого сам в себе не оспаривал. Вообще, во всем «Реквиеме» было для меня что-то необъяснимое». [7].

Мысль и чувство как электричество и магнетизм, электричество порождает магнетизм и магнетизм порождает электричество. Так мысль порождает чувство и чувство порождает мысль. Все во вселенной двойственно, электрон и позитрон, огонь и вода, радость и горе... И сама Вселенная двойственна - проявленная и мнимая, как порядок и хаос, как день и ночь.

СОФЬЯ ГУБАЙДУЛИНА: «Меня привлекает сейчас идея четвертитонов - выявить в звуковой реальности, разницу между одной настройкой и другой настройкой инструментов. Я уже несколько таких сочинений сделала, потому что мне безумно интересно, функционирует это или нет - c тем, чтобы сделать опять же, обрести, как бы ночь. Дело в том, что наша 12-тоновая настройка, 12-тоновая темперация и наше системное мышление совпадают. И получается, что весь материал как бы светлый - он весь в нашей ментальности, он весь структурирован, все 12 тонов участвуют в звуковой системе. И это все день, это все свет. Мы, как бы потеряли ночь с моей точки зрения. И это очень плохо для формы крупного сочинения, потому что некуда идти, и нет причины идти. ... Когда мы в музыкальной системе достигли предела - наша музыкальная система охватывает весь 12-тоновый круг, то - некуда идти, и поэтому, например, у Луиджи 
Ноно есть произведение под названием «Некуда идти, но надо идти» вот, чуткий художник, который осознал причину своей музыкальной боли. «Некуда идти, но надо идти!» Это вполне закономерно, если система совпадает со звуковым материалом, то действительно некуда идти. И вот, я думаю о том, нельзя ли получить ночь, то есть, темное пространство куда выйти и затем прийти с помощью удвоения 12-тоновой системы, то есть разной настройки - на четверть тона различающейся. И тогда существует как бы сюжет, где происходит корреспонденция между темным и светлым, между плюсом и минусом, то есть возвращается жизнь...». [4]

ВАЛЕНТИН СИЛЬВЕСТРОВ: «Недавно я разговаривал с Губайдуллиной. Она, Пярт или Кнайфель, - все они опираются в своих композициях на число. Это такая пифагорейская мысль, что в основе мира лежит число. Я же понимаю так: число - это свет. А исходить нужно не из света, а из полной тьмы. Когда ты исходишь из тьмы, ты не знаешь ни сильной доли, ни слабой, ни пропорций,- вообще ничего. Оно-то все, конечно, существует, но ты о нем еще не знаешь. А вот когда начинаешь узнавать, и возникает число. То есть одно дело, когда ты начинаешь с числа, совсем другое когда ты к числу приходишь. Когда текст написан, он и есть число, родившееся из тьмы».

Наверное, можно сказать, что природа Вселенной стоит на «трех китах», которые есть жизнь, сознание, мысль. Музыка - часть природы, ей присуща жизнь, отклик на конкретную ступень эволюции, ее гармонии и свое мышление. Музыка есть язык, имеющий свою развивающуюся структуру, язык при помощи которого идет диалог между человечеством и Вселенной, при этом всегда остается тайна (для человечества).

АНТОН ВЕБЕРН: «Кто хочет приблизится к произведениям большого искусства, тот должен подходить к ним так, как следует подходить к творениям природы, то есть с должным благоговением перед лежащей в их основе тайной... Но познаем ли мы теперь эту тайну или нет, нам должно быть ясно одно, здесь господствует закономерность, и мы должны относиться к этим законам так же, как к законам, которые мы приписываем природе...». [8]

ЭДИСОН ДЕНИСОВ: «Красота мышления в математике имеет такое же значение как и красота мышления в музыке. Музыка из всех искусств есть тот тип человеческого мышления, которое как можно глубже уходит в глубины духа. Музыка в своих высших проявлениях как и математика доходит до некоторой границы - дальше Бог...». [2]

Фундаментальная троица звук-свет(цвет)-число рассматривалась не только в аспекте звук-число, но и в аспекте звук - цвет (закристаллизовавшийся свет).

ЭДИСОН ДЕНИСОВ: «Живопись и музыка очень близки. Организация пространства в живописи и музыке имеют много общего в своей логике. Краска в музыке может быть так же информативна и важна как и другие компоненты, - мелодия, гармония, ритм... Как в живописи наложенная друг на друга краска постепенно приобретает новое качество, так в музыке при сложных микстурах тембр меняется и получается такой особый эффект, совершенно невидимый, неслышимый... Работа с краской очень интересна». [2] 
АЛЕКСАНДР СКРЯБИН: «Бемольные тональности имеют какой-то металлический блеск, а диезные - яркие, насыщенные по цвету и без такого металлического блеска. Я всегда различаю их именно по этому цветовому тону.

( $\mathrm{O}$ «рометее): Мне нужен был свет в музыке... мне нужна была лучезарная гармония, которая отображала бы ИДЕЮ СВЕТА. И я ее получил вот по какому соображению. Я рассудил, что чем больше верхних звуков у гармонии, тем она вообще лучезарнее, тем она острее и ослепительнее. Но надо было эти звуки так упорядочить, чтобы это было единственно логичное. Я взял расположенный по терциям обыкновенный терцдецимааккорд... Но мало накопить эти верхние звуки. Чтобы это было лучезарно, чтобы это отражало идею света, надо чтобы в этом аккорде было наибольшее число повышенных звуков. И вот я повышаю, сначала беру терцию непременно большую, светлую и мажорную, потом квинту тоже повышаю, потом повышаю и ундециму - вот получился у меня мой аккорд - который весь повышенный и оттого действительно лучезарный.

Должно быть соответствие между светом и звуком - оно необходимо, иначе бессмыслица, нет единства...». [5]

Композиторы искали в музыке звучание бесконечности, вечности, вселенских циклов проявления и растворения космической материи...

АЛЕКСАНДР СКРЯБИН: «В «Прометее» у меня будут такие медленные темпы, как никогда ни у кого не было, медленные как угодно - они должны длиться как вечность, - потому, что ведь это вечность должна пройти от момента томления до полной материализации... У меня будут и такие быстрые темпы, как никогда не были, в самом конце. В этот самый момент и будет созерцание гармонии, и наступит дематериализация, потому что это - одно и тоже».

АЛЬФРЕД ШНИТКЕ: «Раньше мне важна была конечность, материальность, кристальность формы. Сейчас меня больше привлекает ее бесконечность, летучесть, неопределенность».

Дифференциация в области наук и направлений в искусстве в XX веке достигла невиданного масштаба, но сквозь эту дифференциацию уже просвечивалось нагистральное направление XXI века- синтез, поиск Единства. О поиске общих корней всех наук и искусств в начале XX века Василий Кандинский писал: «... мы получаем безусловное подтверждение наших предположений единого корня всех явлений, выходящих на поверхность предельно различными и совершенно оторванными друг от друга. Именно сегодня нам представляется неизбежной необходимость поиска общих корней. Подобная необходимость не появляется на свет без внутреннего основания и потребует столько упорных попыток, сколько будет нужно. Необходимость этого интуитивного свойства. Дальнейшее - это гармоничная связь интуиции и расчета, - ни первой, ни второй по отдельности недостаточно для продолжения пути» [10].

АЛЕКСАНДР СКРЯБИН: «Искусства были когда-то ранее слиты воедино, ведь они потом разъединились. Вот, если нарисовать точку и из нее несколько линий. Вот эти лини - отдельные искусства, выходящие из одной точки, из точки своего слитного состояния. Искусство зависит от космического процесса, оно не само по себе. Космический процесс (эон) приходит к концу, все воссоединяется. Есть такой же пункт воссоедине- 
ния и в искусстве. Это и есть эта самая Мистерия.Чтобы достигнуть Этого пункта воссоединения, мне не надо двигаться по всем линиям, достаточно двигаться по одной из них, и я все равно попаду в эту точку.

...гармония и мелодия - это две стороны одного принципа, одной сущности, они сначала в классической музыке все разъединились - это процесс дифференциации, это падение духа в материю, пока не стала мелодия и сопровождение, как у Бетховена. А теперь у нас начинается синтез: гармония становиться мелодией и мелодия - гармонией... И у меня нет разницы между мелодией и гармонией - это одно и тоже. ...

Мистерия - это кристалл гармонии... когда в насыщенный раствор посадить кристалл, то весь раствор быстро кристаллизуется... В мире, который есть раствор и этот раствор уже насыщен, образуется в одном месте кристалл, где гармония ВСЕГО осуществлена: это и есть Мистерия». [5]

Музыка XX века, обращаясь к мыслям о дальних мирах не могла не отражать положение дел своего времени. На вопрос какое событие вызвало самое сильное переживание, Альфред Шнитке ответил: «Взрывы атомных бомб в Японии».

АНТОН ВЕБЕРН: «Положение в мире становится все более ужасным, особенно в области искусства. А наша задача становится все более огромной».

АРНОЛЬД ШЕНБЕРГ: «Искусство - вопль, который издают люди, переживающие на собственной шкуре судьбу человечества».

Этот полный боли крик души Шенберга, конечно, не может быть определением искусства. Творение искусства - божественный дар человечеству, то, что открывает людям все новую и новую красоту и гармонию мира. Искусство - это творческий труд или Молитва. И в том, что человечество, в целом, выжило в ХХ веке есть заслуга коллективного творческого труда музыкантов, - их коллективной молитвы и мыслям о мире и красоте в самые трудные периоды человеческой истории.

СОФЬЯ ГУБАЙДУЛИНА: «Моя боль - это разрыв между цивилизацией и культурой... Но я думаю, что искусство - это спасение человечества... Искусство для того и создано, чтобы соединиться с Небом». [9]

В XXI веке музыкальный «рай» включил в себя классику XX века и теперь у музыкантов есть время задуматься о новых смыслах...

24.03.2020

P.S. Сегодня итальянский тенор Адреа Бочелли пел в пустом Кафедральном Соборе Милана, его Концерт назывался «Music for Норе», его слушали одновременно онлайн почти 3 миллиона человек.

Французский тенор Стефан Сенешаль поет из окна для жителей своей улицы в Париже, на балконах Вены играют музыканты ...

Пандемия загадочного вируса, - пустые улицы Нью-Йорка, Лондона, Парижа, Милана, Киева... - музыка как спасение... 


\section{Литература}

1) Webern Anton.1960. Der Weg zur Neuen Musik. (vortrag von 27.02.1933). Universal edition https://www.academia.edu/9337835/anton_webern der_weg_zur_neuen_musik

2) Эдисон Денисов. Преодоление жизни : документальный фильм. 1993. / реж. Татьяна Андреева.

3) Шульгин, Д.И. 1993. Беседы с композитором. Годы неизвестности Альфреда Шнитке. Москва : Из-во Деловая Лига.

4) Губайдулина, С. С моей точка зрения: Интервью Д. Смирнова 9 июня 2001. / [записал] Д. Смирнов. http://website.lineone.net/dmitrismirnov/ GubaidRus.html.

5) Сабанеев, Л.Л. 2000. Воспоминания о Скрябине. Москва. (по изданию 1924 г.)

6) Шнитке А. 1982. На пути к воплощению новой идеи. Проблемы традичий и новаторства в современной музыке. Москва : Советский композитор. 104-107.

7) Беседы с Альфредом Шнитке 1994. / Соствитель, автор вступ. ст. А.В. Ивашкин. Москва: РИК «Культура»

8) Webern Anton.1960. Der Weg zur Neuen Musik (vortrag von 20.02.1933). Universal edition https://www.academia.edu/9337835/anton_webern_ der_weg_zur_neuen_musik

9) Сад радости в мире печали : документальный фильм. 2011 / реж. Андрей Торстенсен.

10) Kandinskij, Vasilij. 1926. Punkt und Linie zu Fleache. Meunchen. A. Langen.

11) Сильвестров, Валентин. 2012. Дождаться музыки (Лекции и беседы с С. Палютиковым). Киев : ДУХ І ЛІТЕРА.

\section{Referenses}

1) Webern Anton.1960. Der Weg zur Neuen Musik. (vortrag von 27.02.1933). Universal etdition https://www.academia.edu/9337835/anton_webern_ der_weg_zur_neuen_musik

2) Edison Denisov. Preodolenie zhizni : dokumentalnyiy film. 1993 / rezh. Tatyana Andreeva.

3) Shulgin, D.I. 1993. Besedyi s kompozitorom. Godyi neizvestnosti Alfreda Shnitke. Moskva : Iz-vo Delovaya Liga.

4) Gubaydulina, S. S moey tochka zreniya: Intervyu D. Smirnova 9 iyunya. 2001 / [zapisal] D. Smirnov. http://website.lineone.net/dmitrismirnov/ GubaidRus.html

5) Sabaneev, L.L. 2000. Vospominaniya o Skryabine. Moskva. (po izdaniyu 1924 g.).

6) Shnitke A. 1982. Na puti k voploscheniyu novoy idei. Problemyi traditsiy $i$ novatorstva $v$ sovremennoy muzyike. Moskva : Sovetskiy kompozitor. 104-107. 
7) Besedyi s Alfredom Shnitke. 1994 / Sostvitel, avtor vstup.st. A.V. Ivashkin. Moskva: RIK «Kultura».

8) Webern Anton.1960. Der Weg zur Neuen Musik (vortrag von 20.02.1933). Universal etdition https://www.academia.edu/9337835/anton_webern der_weg_zur_neuen_musik

9) Sad radosti v mire pechali : dokumentalnyiy film, 2011. / rezh. Andrey Torstensen.

10) Kandinskij, Vasilij. 1926. Punkt und Linie zu Fleache. Meunchen. A. Langen.

11) Silvestrov, Valentin. 2012. Dozhdatsya muzyiki (Lektsii i besedyi s S. Palyutikovyim). Kiev : DUH I LITERA. 